Purdue University

Purdue e-Pubs

\title{
Autopilot programming and operations within an unmanned aerial systems course
}

Brian Kozak

Purdue University - Main Campus, bkozak@purdue.edu

Follow this and additional works at: https://docs.lib.purdue.edu/aseeil-insectionconference

Kozak, Brian, "Autopilot programming and operations within an unmanned aerial systems course" (2019). ASEE IL-IN Section Conference. 3.

https://docs.lib.purdue.edu/aseeil-insectionconference/2019/technology/3

This document has been made available through Purdue e-Pubs, a service of the Purdue University Libraries. Please contact epubs@purdue.edu for additional information. 
Autopilot programming in an Unmanned Aerial Systems (UAS) course

\begin{abstract}
Students majoring in unmanned aerial systems (UAS), commonly known as drones, are expected to have a diverse background of hands-on and theoretical skills. Since the UAS industry is rapidly growing at approximately $30 \%$ per year, quality graduates are in high demand. A junior level course on autonomous aerial vehicles has been created to provide this blend of these essential skills required by the UAS industry. Concepts related to navigation, control, regulations, guidance, airspace, and autopilot programming are introduced during the twice weekly, one-hour lecture. These topics are reinforced during a once weekly, two-hour laboratory where students in groups of two work during the first third of a fifteen-week semester to integrate an open source, open hardware autopilot into a $3 \mathrm{~d}$ printed quadcopter. The second third of the semester involves students flight testing their vehicle in outdoor conditions and obtaining real-time telemetry for post flight review. The final third of the semester requires students to fly a simulated package delivery mission where the quadcopter auto takes off, navigates through a series of waypoints, auto lands on a target, and finally returns to launch. The vehicle must fly the entire missions without human interaction. By combining both hand-on and theoretical skills, students who complete this course have a valuable skillset which is in high demand by the UAS industry.
\end{abstract}

Key Words: UAS, Pixhawk, Autopilot, Telemetry 


\section{Introduction}

Unmanned aerial systems (UAS), commonly known as drones, have been around since the early days of flight. One of the first UAS was the Kettering Bug which was a military aerial torpedo. It first flew in 1918. However, during most of the $20^{\text {th }}$ century, UAS were limited to military applications due to their cost. Within the last 20 years, due to the miniaturization of integrated circuits and the dropping cost of computers, UAS have become increasingly popular. According to the Federal Aviation Administration (FAA), the agency that regulates aviation within the United States, UAS has grown at $30 \%$ per year (FAA, 2018). Also, the FAA considers a UAS weighing between 0.55 and $55 \mathrm{lbs}$ to be an aircraft under current regulations.

In addition to growing rapidly, the UAS industry evolving quickly. In traditional aviation, a generation of aircraft could last 20-30 years. Large transport category aircraft manufactured by Boeing, Airbus cost tens or hundreds of millions of dollars to purchase and their engineering costs are in the billions of dollars. However, a generation of UAS could be between 6 months and 2 years (FAA, 2018). This large disconnect is due to the size, regulation, and purpose of the different aircraft. In additional, this disconnect between legacy aerospace and UAS, has provided unique challenges.

In order to capitalize on this growing part of aviation, students at a major university have the opportunity to earn a 4 year, Bachelor of Science degree in Unmanned Aerial Systems. These programs must be fluid otherwise the rapid change of technology would leave student with out of date skills. In order to provide students with skills needed for the growing industry, a junior level course on integrating and programming UAS autopilots has been developed. The course focused on using engineering and engineering technology programs as guidance course structure.

\section{Literature Review}

Hands on learning projects have long been part of engineering and engineering technology programs (Carlson \& Sullivan, 1999). Within these programs, hand on projects are a fundamental part of most courses. Dutson et al. (1997) wrote that hands on projects are a tool that is used to combine practical and analytical knowledge. Furthermore, Knight et al. (2007) wrote that projects are most effective when they combine both hands on and team based learning. Projects that are designed to mirror real world challenges are increasingly popular as they challenge students to think as they would in their future careers. Practical projects also encourage students not just to identify to solve problems provided by course instructors but develop tools to their own ones, and accept a higher level of responsibility. Furthermore, these projects combine theoretical and practical engineering concepts. (Schachterle \& Vinther, 1996).

\section{Background on course}

The junior level, 3 credit hour course was taught during a 15 week semester. The course had twice weekly 1 hour lecture and once weekly 2 hour laboratory. Students enrolled in the course were either majoring or minoring in unmanned aerial systems. The ones minoring in UAS had majors primarily in Professional Flight, Aviation Management, or Aeronautical 
Engineering Technology. Prerequisites for the course included one course in quadcopter construction and another in the history of unmanned systems.

During lecture, concepts related to autopilot history, programming, and navigation were introduced. Additional time was spent on open source hardware and software, flight planning, telemetry analysis, and crew resource management. These concepts were built upon and reinforced during the laboratory. Students worked in groups of two to complete the project. They were allowed to work at their own pacing with three deadlines spaced equally throughout the semester.

The autopilot

Students were provided a Pixhawk Cube, formerly known as the Pixhawk 2.1, autopilot. The Pixhawk, Figure 1, was developed as an open source and open hardware autopilot. It has a 32 bit processor running at $186 \mathrm{MHz}$ with $256 \mathrm{~kb}$ of RAM, 2mb of flash memory, and 32 bit failsafe co-processor. The autopilot has two inertial measuring units as well as GPS (Pixhawk, 2018).

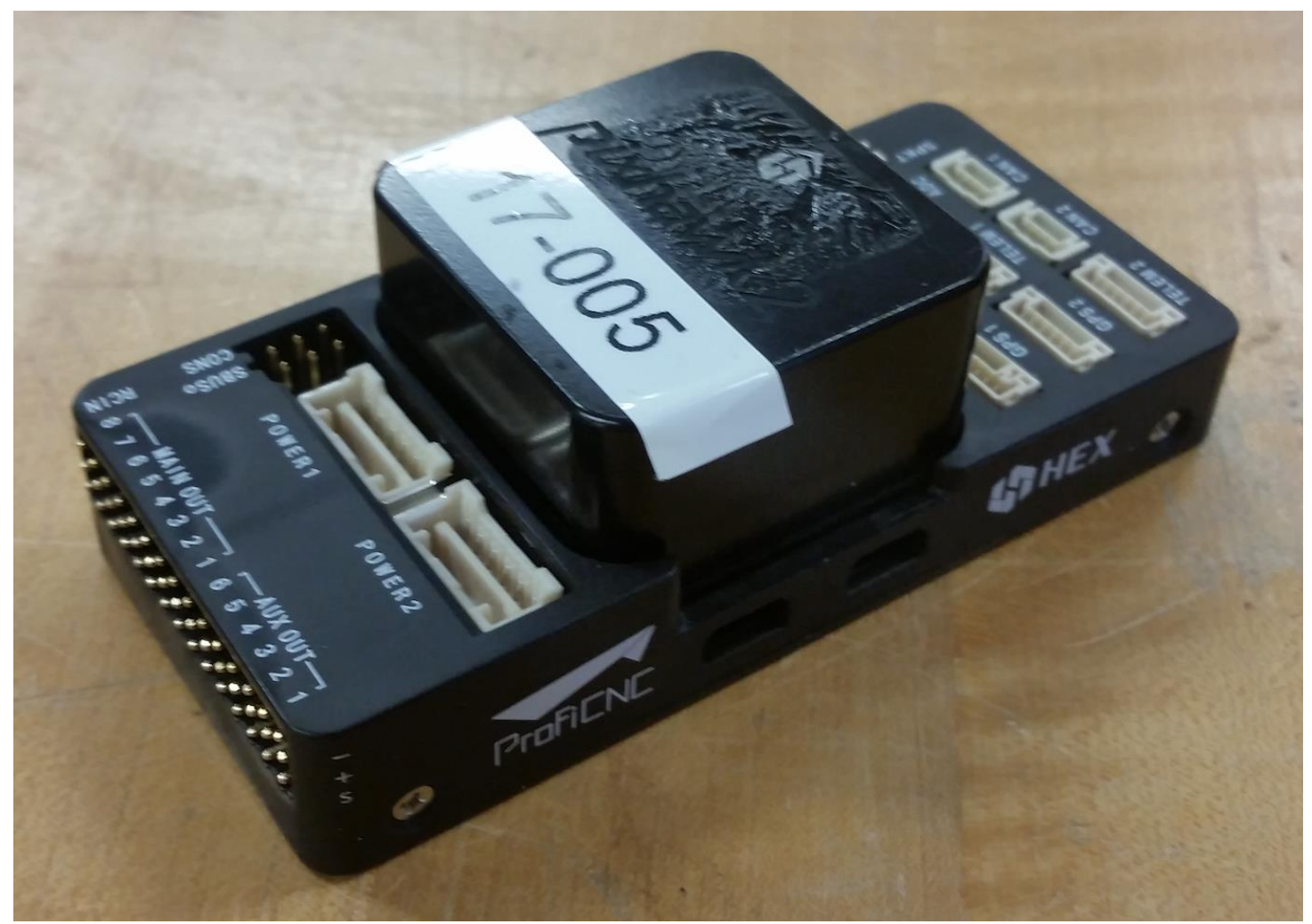

Figure 1. Pixhawk autopilot

Integration of autopilot

A 3d printed quadcopter $550 \mathrm{~mm}$ frame was used for project. It allowed for easy manufacture of spare parts using PLA plastic. The frame had motors, ESC, battery, and related wiring preinstalled. The goal was to mount the autopilot on the frame and connect the wiring to allow for the autopilot to act as a flight controller in manual mode and to autonomous fly in auto 
mode. Once it was physically installed, the firmware on the autopilot was configured using a laptop connected to the autopilot via a micro USB cable. Ardupilot was used as its an open source software suite designed to program the Pixhawk. It was also important for students to verify that the software version of both the Pixhawk and Ardupilot were compatible. Figures 2 and 3 shows the quadcopter with autopilot mounted.

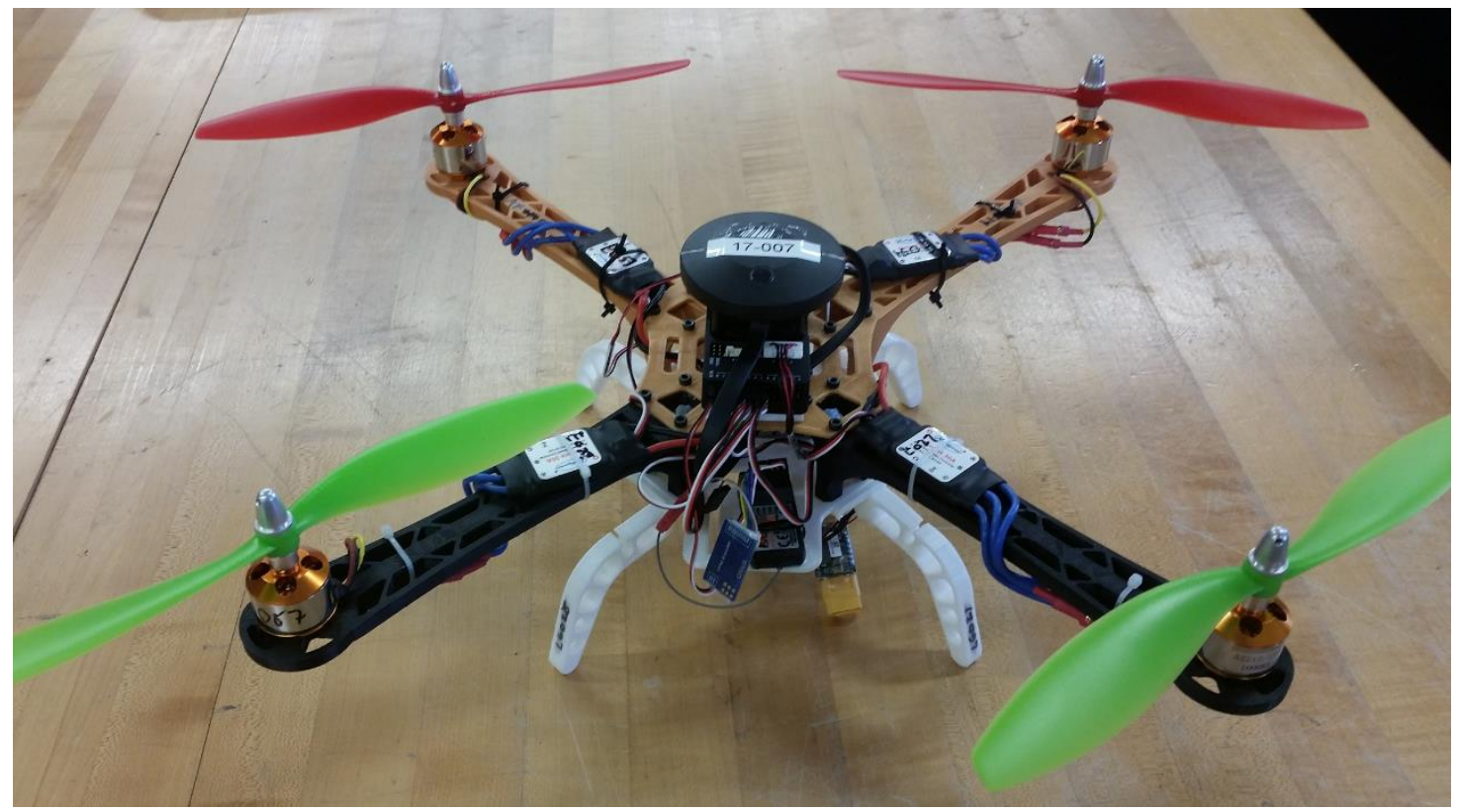

Figure 2. Quadcopter

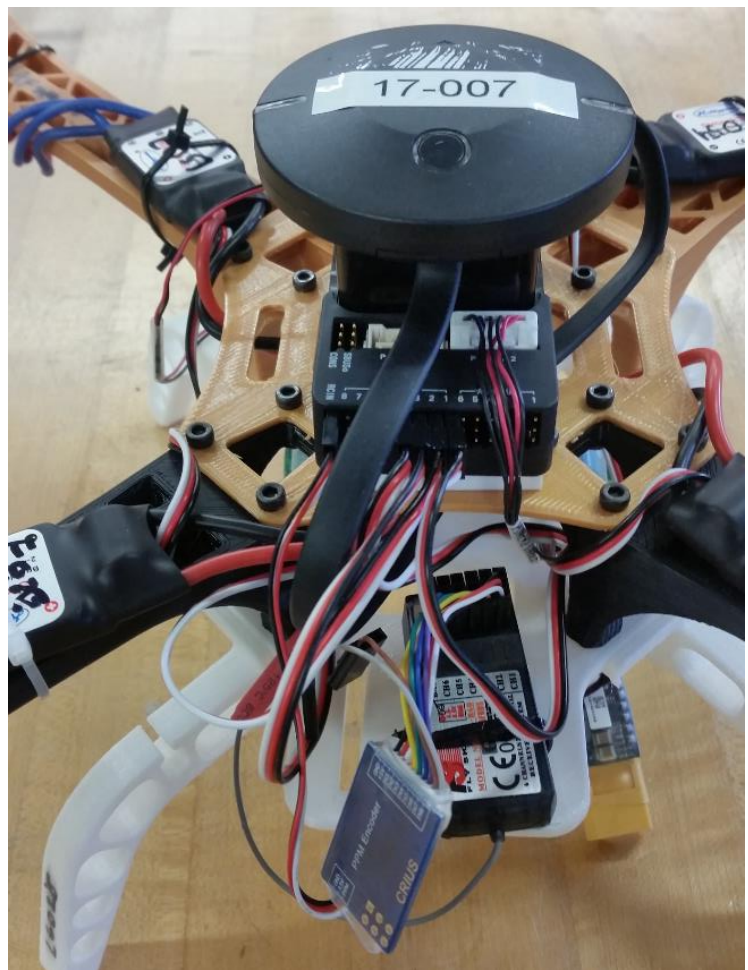

Figure 3. Pixhawk with GPS mounted on a 3d printed quadcopter 
Flight test

Once the autopilot was installed and software configured, the vehicle was flight tested indoors to verify proper set-up. The flight area allowed for free flight inside a box approximately $10 \mathrm{~m}$ by $10 \mathrm{~m}$ by $7 \mathrm{~m}$. The first flight almost always showed issues related to hardware and/or software configuration. A common problem was the reversal of channels controlling pitch, roll, and yaw. Occasionally throttle control was reversed which resulted in the vehicle hitting the ceiling of the building.

Students were required to troubleshoot and fix any problems with their vehicle. However, the cause of the problems sometimes was readily apparent. For example, during the reversal of channels, the error to could have been: with the controller, the ESC, the autopilot firmware, propeller calibration, or operator. Although frustrating at the time, feedback at the end of the semester was mostly positive as they learned valuable skills relating to troubleshooting and fault identification.

After the vehicle was tested indoors, it was test flown outside, Figure 4. The flight area was an open field approximately $500 \mathrm{~m}$ by $500 \mathrm{~m}$. Appropriate FAA rules and regulations were followed. Each group had two crew positions: the first was the operator who was responsible for actual control of the vehicle, the second was the visual observer who was responsible for informing the operator of any obstructions near the flight path. Prior to outdoor flight, the students themselves determine who would be assigned to each position. Furthermore, an exercise in crew resource management was conducted during the lecture portion of the course to develop a sense of teamwork within the group and to promote communication skills

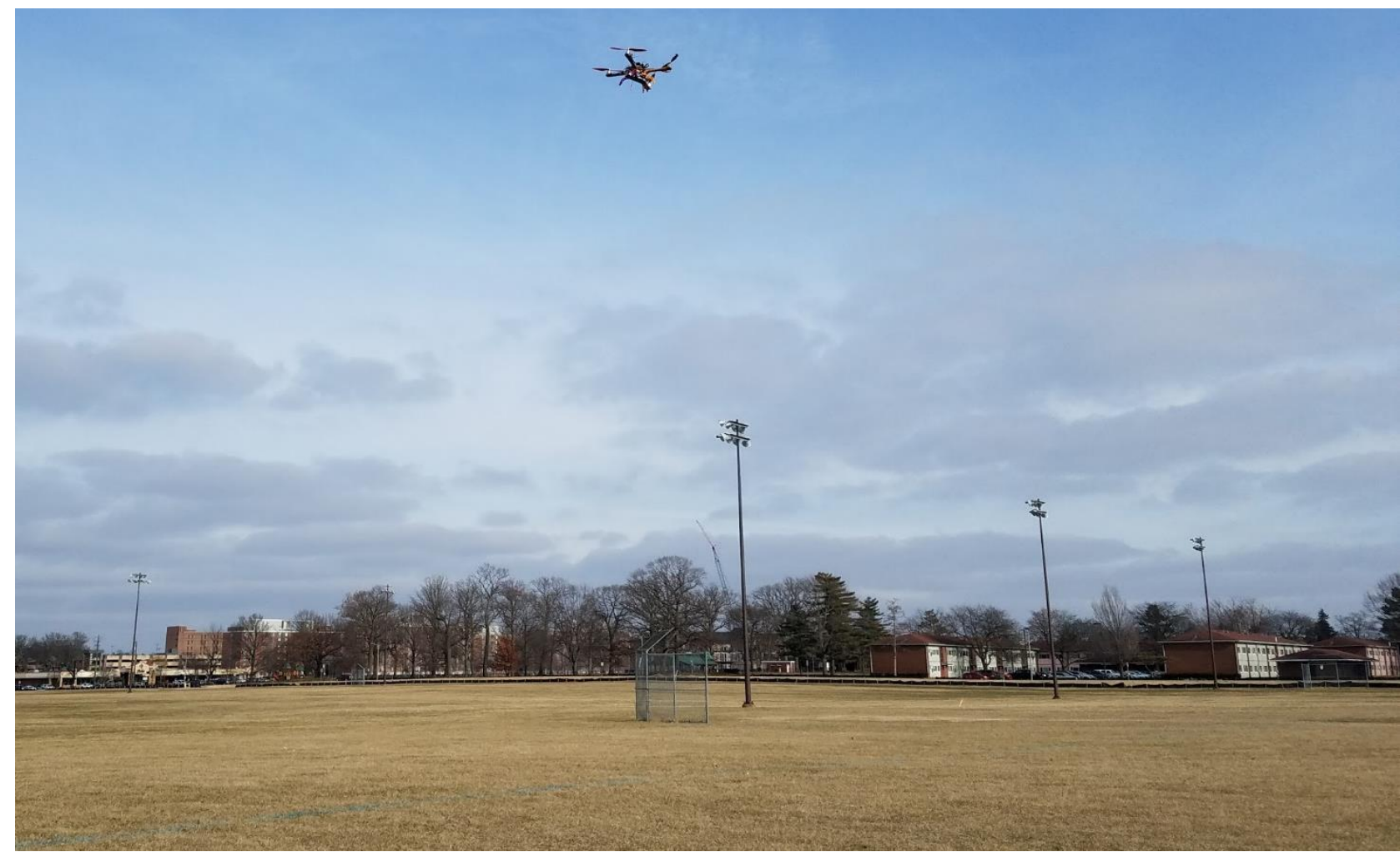

Figure 4: Pixhawk controlled quadcopter flying outdoors 
As part of the course, each student group developed their own set of weather limitations. Current weather from the local Automated Terminal Information Service (ATIS) was checked against the document to ensure that conditions were within the document and were safe for flight. Although there were variations among each group, a wind speed of less than 20 knots with no visible precipitation was consistent among the groups.

Initial testing was conducted at a height of 5 - $10 \mathrm{~m}$ above ground level (AGL). Before any autonomous flight was initially conducted, a GPS fence was set with a circle of a radius of $250 \mathrm{~m}$ from the middle of the field and a height of $50 \mathrm{~m}$. This fence was tested with a student flying forward the edge of the field with the goal that the vehicle would refuse to fly any further once the fence was reached.

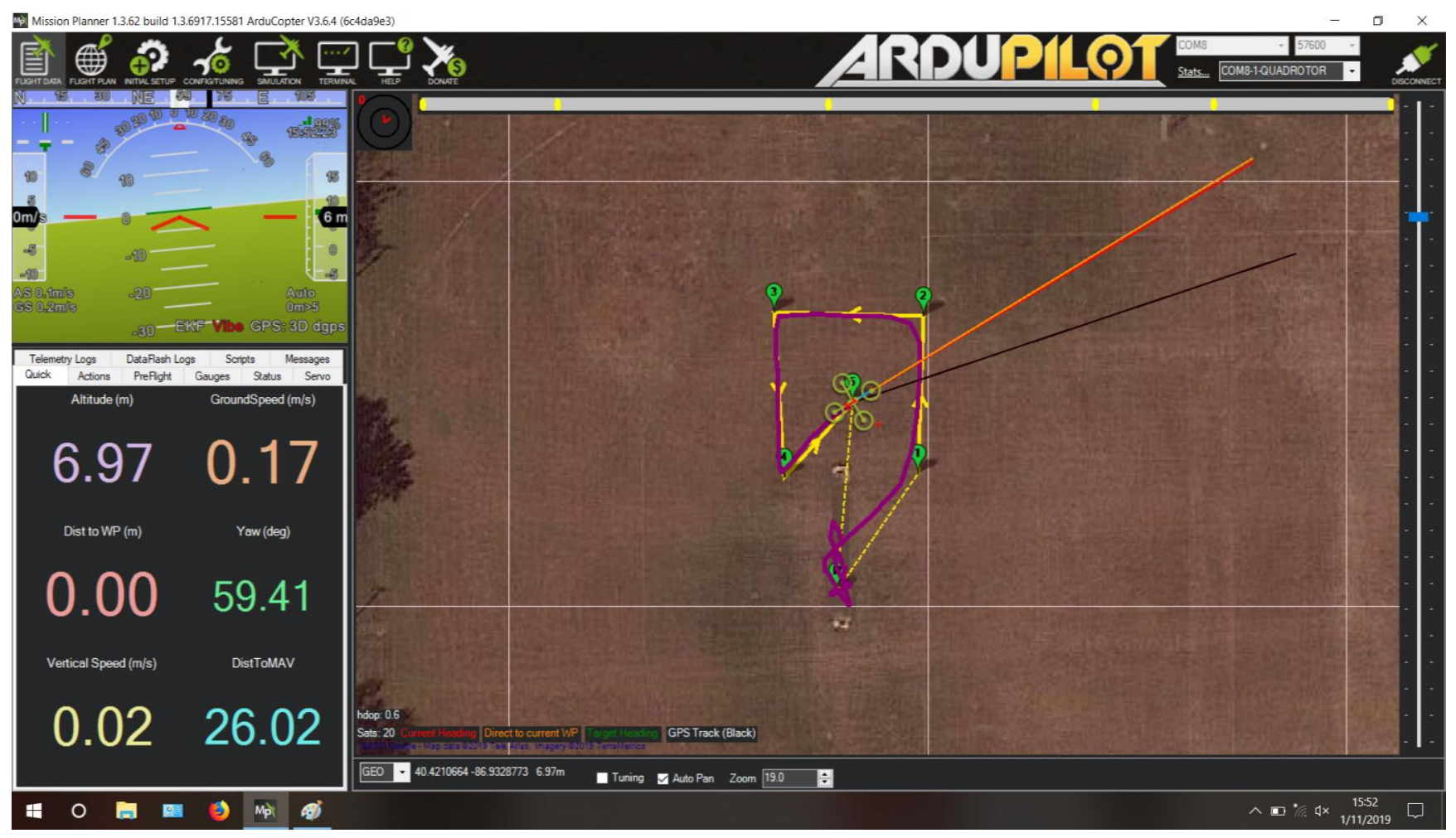

Figure 5: Quadcopter telemetry and ground track

During the project, students were required to monitor real time telemetry from the quadcopter. Data was transmitted via a $915 \mathrm{MHz}$ transmitter from the quadcopter to a ground station. Telemetry was analyzed post flight and was used to refine the programming of the autopilot. Figure 5 shows Ardupilot and quadcopter telemetry with purple ground track.

\section{Simulated mission}

Once the vehicle was flight tested successfully, a simulated delivery mission was programmed into Ardupilot. The goal of the mission was from the quadcopter to takeoff from a starting point, fly at a height of 5-15m AGL, land on a predetermined target, pause for 15-20 
seconds, takeoff again, return to starting, and land without any human input. The mission would start once the operator change the autopilot mode from manual to auto. The visual observer monitor the flight and surrounding area for any obstructions. If needed, post flight telemetry analysis was used to identify problems with the programming and was used in corrections.

During this portion of the course, students earned a grade of either 0 or 50 on the 50 point laboratory assignment. Either the autopilot successfully completed the mission or it did not. The student groups were able to repeat the mission until it was successful or the end of the semester occurred. The simulated mission was accomplished by most student groups in either 1 or 2 attempts. Figure 6 shows a mission with the vehicle flying toward the landing location.

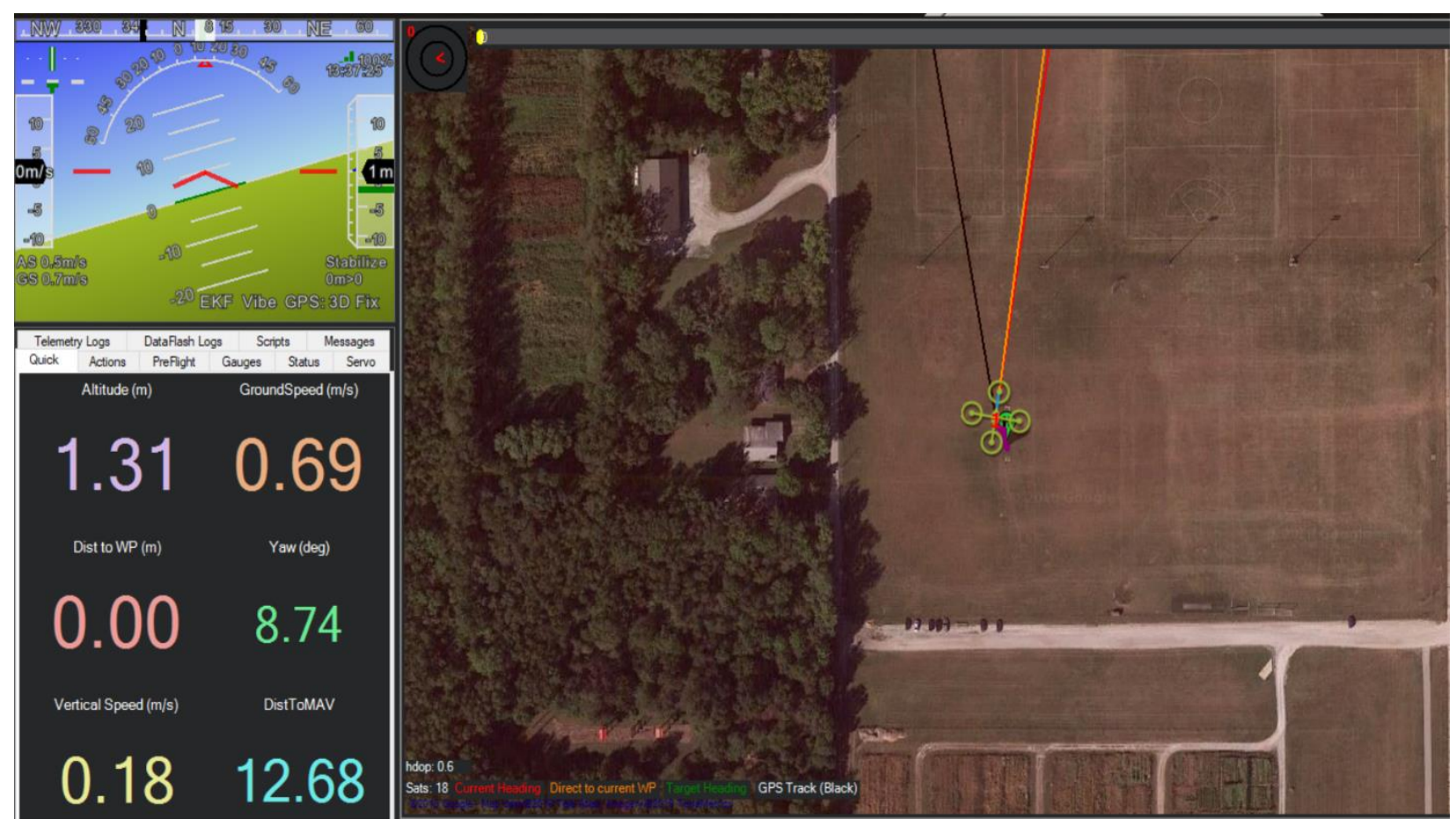

Figure 6: A quadcopter flying in a climbing right turn

Inspiration for this mission came from current UAS companies focusing on package delivery and from the author's contacts with UAS business executives.

\section{Course assessment}

In order to document the effectiveness of the course and material taught and after obtaining Institutional Review Board approval, pre and post seven point Likert scale surveys were given. Students rated their knowledge and comfort of concepts relating to flight planning, autopilot programming and different types of quadcopter control. During the Fall 2018 semester, 19 students took part in the optional survey and rated their knowledge and comfort of various course topics. 
Students rate themselves using the following scale:

1-Not at all, -Slightly, 3-Somewhat, 4-Moderately, 5-Knowledgeable, 6-Very, 7-Extremely

The results are summarized in Table 1 and Table 2

Table 1: Student knowledge of course topics

\begin{tabular}{lccc}
\hline \multicolumn{4}{c}{ Rate your knowledge } \\
\hline & Pre & Post & Delta \\
\hline Flight planning & 4.9 & 6.3 & 1.4 \\
\hline Autopilot programming & 3.6 & 5.5 & 1.9 \\
\hline Flight testing & 5.7 & 5.9 & 0.2 \\
\hline Manual control & 5.8 & 6.2 & 0.4 \\
\hline Autopilot control & 4.5 & 6.1 & 1.6 \\
\hline
\end{tabular}

Table 2: Student comfort of course topics

\begin{tabular}{lccc}
\hline \multicolumn{4}{c}{ Rate your comfort } \\
\hline & Pre & Post & Delta \\
\hline Flight planning & 5.1 & 6.0 & 0.9 \\
\hline Autopilot programming & 3.8 & 5.5 & 1.7 \\
\hline Flight testing & 5.1 & 5.6 & 0.5 \\
\hline Manual control & 5.7 & 5.9 & 0.2 \\
\hline Autopilot control & 4.6 & 5.5 & 0.9 \\
\hline
\end{tabular}

Furthermore, a student provided the following comment on the survey sheet:

The author's approach to this course is unique, yet it is helpful as it forces the students to think on applications of UAS, the unprecedented nature of the regulations, and the history of UAS. -Student 1

During the semester, the five areas of survey all showed increases in student selfperception of knowledge and comfort. The greatest was on autopilot programming. However, since the course was primarily an autopilot course, the increase is expected. Flight test and autopilot control also showed increases. 


\section{Conclusion}

As of an UAS course, students were required to integrate, programming, and fly an autopilot. This multi-week project was broken into three major tasks which taught students skills needed for the future careers. Theoretical skills were first introduced during lecture and were built upon in the laboratory. These fundamental skills are a key part of a rapidly developing industry. The author plans on continuing to work with UAS industry leaders to instructor students in which skills are needed for a generation of aviation leaders.

\section{Future Works}

Student survey data was collected only during the Fall 2018 semester. Since the course is new, it would be beneficial to determine if there is a change in student comfort and/or knowledge from semester to semester and year to year. The author plans to continue development of the course as the goals and needs of the rapidly changing UAS industry evolve Also, students could use telemetry from the Pixhawk to evaluate possible quadcopter modifications would be useful.

\section{References}

Carlson, L. E., Sullivan, J. F. (1999). Hands-on Engineering: Learning by Doing in the Integrated Teaching and Learning Program. International Journal of Engineering Education, 15, 20-31. Retrieved from:

http://citeseerx.ist.psu.edu/viewdoc/download?doi=10.1.1.496.2168\&rep=rep1\&type=pdf

Dutson, A. J., Todd, R. H, Magleby, S. P., Sorensen, C. D. (1997). A Review of Literature on Teaching Engineering Design through Project-Oriented Capstone Courses. Journal of Engineering Education, January 1997, 17-28. Retrieved from: https://onlinelibrary.wiley.com/doi/epdf/10.1002/j.2168-9830.1997.tb00260.x

Federal Aviation Administration [FAA] (2018). FAA Aerospace Forecast 2018-38. Retrieved from: https://www.faa.gov/data_research/aviation/aerospace_forecasts/media/FY201838_FAA_Aerospace_Forecast.pdf

Knight, D. W., Carlson, L. E., Sullivan, J. F. (2007). Improving Engineering Student Retention through Hands-On, Team Based, First-Year Design Projects. International Conference on Research in Engineering Education. Retrieved from: https://itll.colorado.edu/images/uploads/about_us/publications/Papers/ICREEpaperfinalin 07octJEE.pdf

Pixhawk (2018). Cube flight controller. Retrieved from https://docs.px4.io/en/flight_controller/pixhawk-2.html

Schachterle, L., Vinther, O. (1996) Introduction: The Role of Projects in Engineering Education. European Journal of Engineering Education, 21:2, 115-120. Retrieved from: https://www.tandfonline.com/doi/pdf/10.1080/03043799608923394 